\title{
Innovative Teaching and Learning Process with Multidisciplinary approach: An Illustration on Engineering Education
}

\author{
B.Sailaja ${ }^{1}$, K.Hemalatha ${ }^{2}$ \\ ${ }^{1}$ ComputerScience\&Engineering, VJIT, Hyderabad, Telangana \\ ${ }^{2}$ ComputerScience\&Engineering, VJIT, Hyderabad, Telangana \\ ${ }^{1}$ sailaja@ vjit.ac.in \\ 2hemalatha@vjit.ac.in
}

\begin{abstract}
Education is the most powerful weapon to change the world. The education in engineering begins with theories and progressing to the application of learnt theories. Different methods exist in engineering teaching and learning process. Teaching can be done in many waysGenerally by giving lectures, demonstrations and deliberations. These ways focuses on principle content, emphasizing memory, applications, and understanding the subject. Learning by a student happens in many ways - by seeing and hearing, reflecting and acting, memorizing and visualizing and drawing analogies and building mathematical models. This paper mainly emphasis on innovative methods of teaching and learning process with multidisciplinary approaches to increase the standards of the engineering education and an illustration on engineering education.
\end{abstract}

Keywords: Multidisciplinary, Innovation, Illustration, Instructors, Engineering Education, Knowledge, Current Techniques, Modern Tools

\section{Introduction}

Education is an engine for the growth and progress of any society. It not only imparts knowledge, skills and inculcates values, and also responsible for building human capital which breeds, drives and sets technological innovation and economic growth. When there is a willingness to change, there is a hope for progress in any field. The developed creativity and innovative methods benefits both students and teachers.

Education is not filling the mind with a lot of facts. Perfecting the instrument and getting complete mastery of my own mind. - Swami Vivekananda

Instructors have to convert education into a sport and learning process has to generate interest in the students and motivate them to stay back in the institution than to run away from it. Education should become a fun and thrill to them rather than burden and boredom. It is an integral part of their growth and helps them become good citizens. No one was ever really taught by another; each of us has to teach them self. The external teacher offers only the suggestion which rouses the internal teacher to work to understand things. - Swami Vivekananda

New technologies are giving to recourse. Academics are exploiting the new technologies of multimedia and Internet. As well, universities are experimenting with alternative teaching strategies-such as problem-based learning and case-based learning, etc - to expand the range of learning outcomes and increase the relevance of student learning to future careers.

\section{A. Significance of Innovation in Teaching and Learning}

Being innovative is about looking beyond what we currently do well, identifying the great ideas of tomorrow and putting them into practice.

Today's students want an education that meets their individual needs, and opportunities that connect them to

\author{
B.Sailaja ${ }^{1}$ \\ ${ }^{1}$ ComputerScience\&Engineering, VJIT, Hyderabad, \\ Telangana \\ ${ }^{1}$ sailaja@vjit.ac.in
}


what is happening around the globe. They challenge teachers to be innovative and to make learning environments more exciting, challenging and rewarding.

Learning forums are transparent and multidisciplinary. Learners use technology creatively to move beyond the classroom walls and transform education through innovative approaches. Innovative approaches strengthen the ideas that are applied in the development of the human goal.

Innovative process improves the knowledge and understands how to experiment with new possibilities in order to implement new concepts which creates new value. The process of innovation is

- identify a need for innovation

- learn from others - adapt and enhance existing ideas

- plan and run your trial

- share your ideas.

This process enhances the quality of education which leads to the progress and development of higher education.

\section{Related Work}

Traditional teaching and learning process comprises of three types.

\section{Explaining}

Explaining or lecturing, is the process of teaching by giving spoken explanations of the subject that is to be learned. Lecturing is often accompanied by visual aids to help students visualize an object or problem.

\section{Traditional Teaching Method:}

Teaching in classroom using chalk and talk is "one way flow" of information.

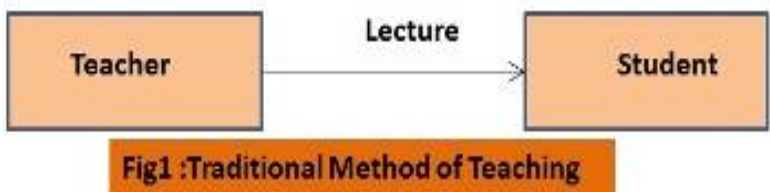

The above fig(1) shows the Traditional approach of teaching where teachers transforms the subject content to the student. Teachers often continuously talk for an hour without knowing students response and feedback. The material presented is only based on lecturer notes and textbooks. Teaching and learning are concentrated on "plug and play" method rather than practical aspects. There is insufficient interaction with students in classroom.

\section{Demonstrating}

To overcome the problem with traditional approach we go for Demonstration. In the Demonstration process the methodology used is teaching through examples or experiments. Demonstration means "to clear show". For example, a science teacher may teach an idea by performing an experiment for students. A demonstration may be used to prove a fact through a combination of visual evidence and associated reasoning.

Demonstrations are similar to written storytelling and examples in that they allow students to personally relate to the presented information. Memorization of a list of facts is a detached and impersonal experience, whereas the same information, conveyed through demonstration, becomes personally relatable.

\section{Collaborating}

Collaboration allows students to actively participate in the learning process by talking with each other and listening to other points of view. Collaboration establishes a personal connection between students and the topic of study and it helps students think in a less personally biased way. Group projects and discussions are examples of this teaching method. Teachers may employ collaboration to assess student's abilities to work as a team, leadership skills, or presentation abilities.

The reason for going innovative teaching and learning process is, because of the rapid growth in technology, the present generation students are expecting more from teacher. But traditional teaching and learning process is restricted to the prescribed syllabus and there is no exposure to solve real time scenarios. Once the beginner becomes graduate they should be able to work in teams and needs to solve real-time problems, which require better communication skills, creativity and should know current techniques with modern tools. This paper emphasizes on the innovations in teaching and learning process with multidisciplinary approach where a graduate meets their global needs.

\section{Innovations in Teaching And Learning}

To overcome the problems in the traditional teaching and learning process innovative teaching methods came in many forms, which includes problembased learning, project based learning, case-based teaching, E-Learning, Multimedia Learning with multidisciplinary.

\section{A. Problem-based learning}

In problem-based learning (PBL), studentsusually working in teams-are confronted with an illstructured open ended real-world problem to solve, and take the lead in defining the problem precisely, figuring out what they know and what they need to determine, and how to proceed to determine it. They formulate and evaluate alternative solutions, select the best one and make 
a case for it, and evaluate lessons learned. Problem-based learning is seen as an innovative measure to encourage students to learn how to learn via real-life problems.

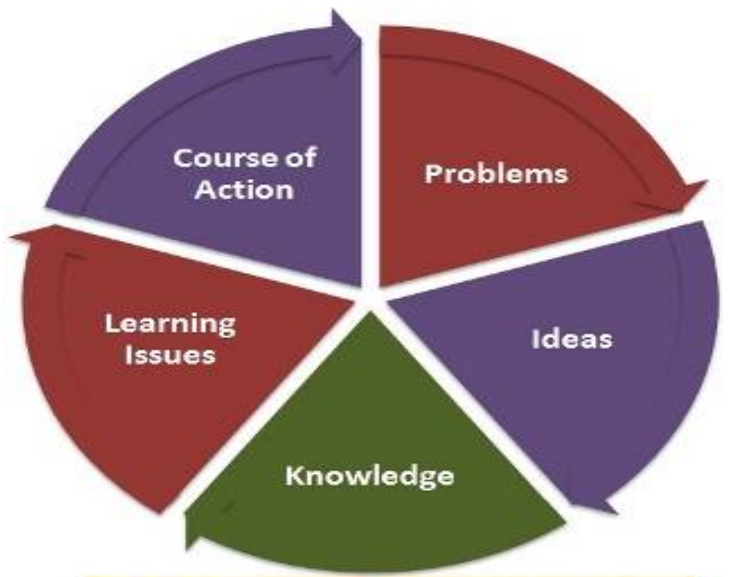

Fig 2:Problem Based Learning

The fig:2 shows steps to solve a problem using PBL

PBL gives students the responsibility of defining the knowledge and skills they need to proceed with each phase of the problem, and so instructors must be prepared to go in directions that may not be familiar or comfortable. Moreover, PBL involves a spectrum of instructional features likely to provoke student resentment and resistance, including complex problems that have no unique solutions, the need for students to define for themselves what they need to know to solve them, and the logistical and interpersonal problems that inevitably arise when students work in teams.

In PBL, class time may be devoted to: (a) groups reporting out their progress on previous learning issues and listing their current learning issues and plans of work, (b) mini-lectures giving information on issues being dealt with by all groups, clarifying common difficulties, and suggesting additional learning issues, and (c) whole class discussion.

\section{B. Project based learning}

Project-based learning begins with an assignment to carry out one or more tasks that lead to the production of a final product - a design, a model, a device, a computer simulation and the analysis and interpretation of the data. The culmination of the project is normally a written or oral report summarizing what was done and what the outcome was.

de Graaf and Kolmos [10] define three types of projects that differ in the degree of student autonomy:

- Task project: Student teams work on projects that have been defined by the instructor, using largely instructor prescribed methods. This type of project provides minimal student motivation and skill development, and is part of traditional instruction in most engineering curricula.

- Discipline project: The instructor defines the subject area of the projects and specifies in general terms the approaches to be used (which normally involve methods common in the discipline of the subject area), but the students identify the specific project and design the particular approach they will take to complete it.

- Problem project: The students have nearly complete autonomy to choose their project and their approach to it.

Project-based learning is similar to problembased learning in several respects. Both normally involve teams of students in open-ended assignments that resemble challenges the students are likely to encounter as professionals, and both call for the students to formulate solution strategies and to continually re-evaluate their approach in response to outcomes of their efforts.

Project-based learning gives learners the opportunity to expand their knowledge base and develop skills through problem solving and investigation. A real world problem or question is at the heart of every projectbased eLearning experience, and learners must conduct research and acquire the necessary information to arrive at their own conclusion.

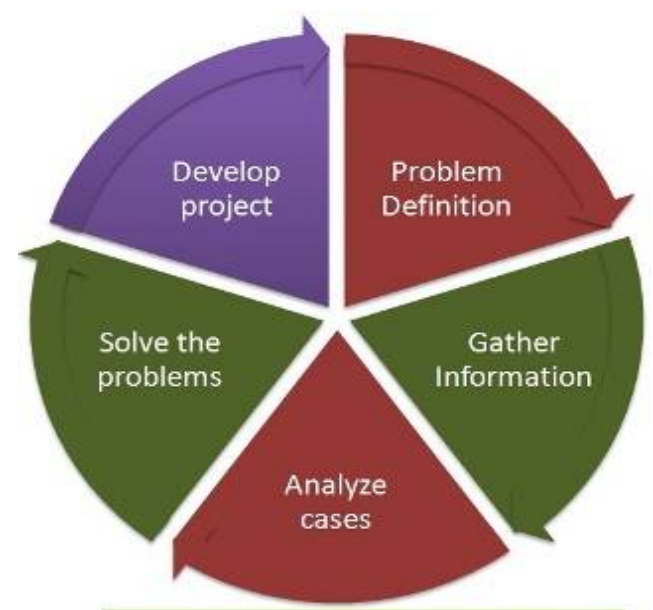

Fig 3:Project Based Learning

The fig:3 shows the how to develop a project for a scenario.

However, there are differences in the two approaches; in project- based learning is on applying or integrating knowledge while that in problem-based learning is on acquiring it.

\section{Case-based teaching}

In case-based teaching, students study historical or hypothetical cases involving scenarios likely to be encountered in professional practice. The case is a complete narrative of a problematic situation, how people dealt with it, and what the outcomes were. Forms of casebased instruction that are inductive use what Lynn [11] calls "teaching cases," in which the circumstances of the case are described but the decisions made by the protagonists are withheld so that the students can do their own analysis and decision making. 


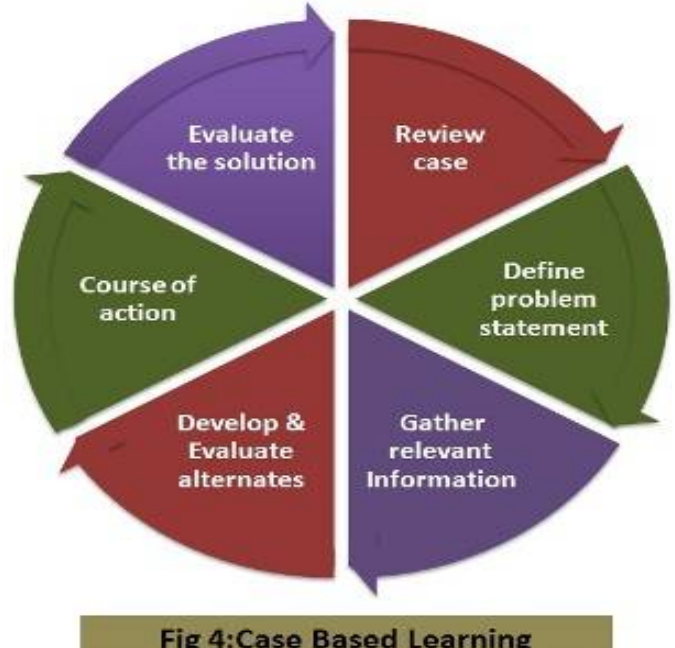

Fig 4:Case Based Learning

Analyses of teaching cases involve several steps shows in fig 4 : (1)review of the case content, (2) statement of the problem, (3) collection of relevant information, (4) development of alternatives,(5) evaluation of alternatives, (6) selection of a course of action, and (7) evaluation of solutions, and possibly review of actual case outcomes.

The use of case studies enhanced students' ability to recognize multiple perspectives, and they also note that the use of cases developed students' ability to identify relevant issues. Studies have shown that relative to conventional teaching, case-based instruction significantly improves student retention, reasoning and problem solving skills.

Lundeberg and Yadav[12] (2006) carried out a meta-analysis and concluded that cases have a positive impact on faculty and student attitudes, class attendance, and faculty perceptions of learning outcomes.

\section{E-learning}

There has been a growing interest in higher education in opportunities for students to learn in the online environment. The appropriate use of technology has great potential to allow a more inclusive approach to student learning and can, if carefully designed, improve the quality of the students' learning experience.

'E-learning is an approach to teaching and learning, representing all or part of the educational model applied, that is based on the use of electronic media and devices as tools for improving access to training, communication and interaction and that facilitates the adoption of new ways of understanding and developing learning' .

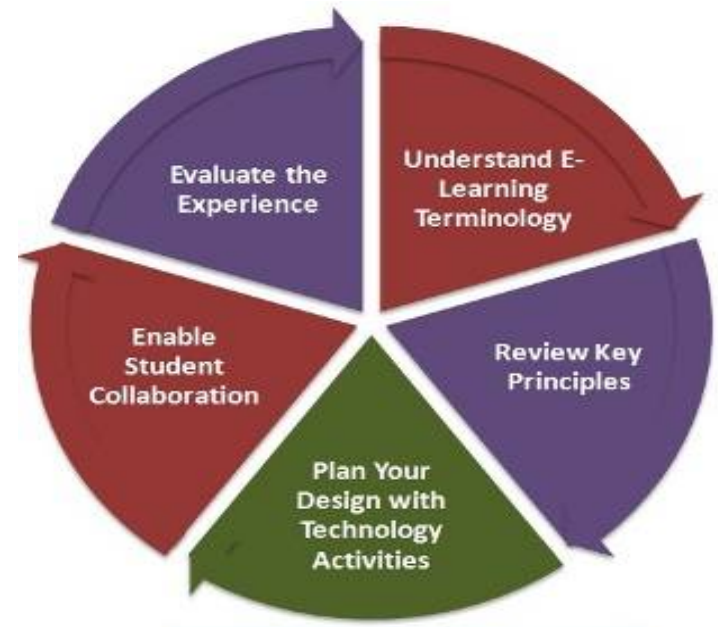

Fig 5:E-Learning

The fig:5 explains how to grab the additional information from the different e-learning resources.

Developing e-learning is more expensive than preparing classroom materials and training the trainers, especially if multimedia or highly interactive methods are used. However, delivery costs for e-learning (including costs of web servers and technical support) are considerably lower than those for classroom facilities, instructor time, participants' travel and job time lost to attend classroom sessions.

There are two general approaches to e-learning: self-paced and facilitated/instructor-led. Self-paced learners are alone and completely independent, while facilitated and instructor-led e-learning courses provide different levels of support from tutors and instructors and collaboration among learners. Often, e-learning courses combine both approaches, but for simplicity it is easy to consider the two separately.

The E-learning section addresses issues of design and implementation of both the on-line and blended learning environments. In addition, particular attention is given to the design and use of Blackboard, UCD's virtual learning environment

\section{E. Multimedia Learning}

Multimedia technology as an innovative teaching and learning strategy in a problem-based learning environment by giving the students a multimedia project to train them in this skill set. Another advantage of creating multimedia projects in the classroom setting is that when students create multimedia projects, they tend to do this in a group environment. By working in a group, the students would have to learn to work cooperatively and collaboratively, using their group skills and a variety of activities to accomplish the project's overall objectives. 
The teacher uses multimedia to modify the contents of the material. It will help the teacher to represent in a more meaningful way, using different media elements. These media elements can be converted into digital form, modified and customized for the final presentation. By incorporating digital media elements into the project, the students are able to learn better since they use multiple sensory modalities, which would make them more motivated to pay more attention to the information presented and retain the information better which shows in the below fig: 6 .

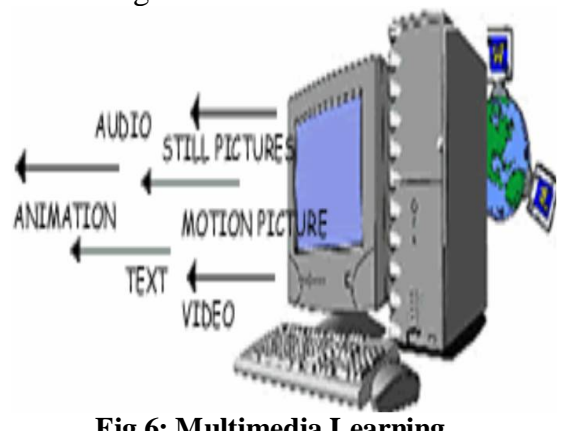

Fig 6: Multimedia Learning

Creating multimedia projects is both challenging and exciting. Fortunately, there are many multimedia technologies that are available for developers to create these innovative and interactive multimedia applications. These technologies include Adobe Photoshop and Premier to create edit graphics and video files respectively, Sound Forge and 3D Studio Max to create and/or edit sound and animation files, respectively.

\section{F. Innovative Tools}

The researchers suggest some of the methods can very well be applied by the modern teachers. As the researchers feel that basically the core objective of teaching should never be deviated by the use of an innovative method. The following methods which are suggested are an extension to the traditional methods of teaching

\section{I)Mind Map}

Mind maps were developed in the late 60s by Tony Buzan as a way of helping students make notes that used only key words and images, but mind map can be used by teachers to explain concepts in an innovative way. They are much quicker to make and much easier to remember and review because of their visual quality. The nonlinear nature of mind maps makes it easy to link and cross-reference different elements of the map. Mind Maps can also be effective mnemonics and remembering their shape and structure can provide the cues necessary to remember the information within it which shows in fig 7. They engage much more of the brain in the process of assimilating and connecting facts than conventional notes.

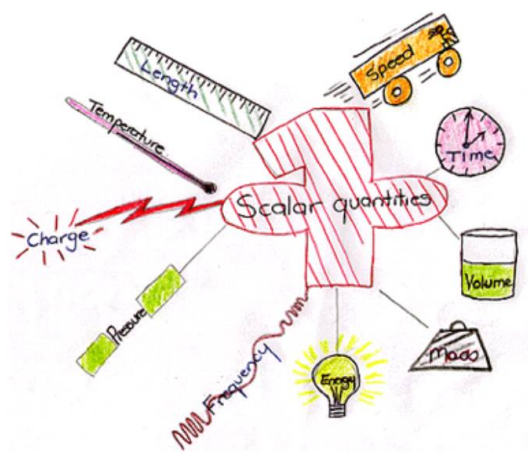

Fig 7: Mind Maps

This would bring very high impact on the minds of the students about a concept

- Creates clear understanding

- PowerPoint can be used widely

- Innovative thinking improves.

\section{II) Mnemonics Words- Words -Words Approach}

Here the teacher is not supposed to talk on a particular concept for a quite long time. But to make it clear to the students he can just go on saying mnemonics or its associated meaning in words. Here he goes on saying only words instead of sentence, and once they come to a basic understanding of the meaning of a particular concept then the teacher will explain in sentences.

For example in teaching language courses this technique can be used as an effective medium by the teacher to develop word power.

\section{G. Multidisciplinary approach in Teaching and Learning}

Present teaching and learning process uses innovative methods to increase the quality of education. Not only using the innovative methods, sometimes multidisciplinary methods are followed in teaching and learning at a time.

Instructor may uses pictures, graphs or any computer assisted instruction for effective teaching for explanation, in the same way a student can understand easily and enthusiast. For this an Instructor follows multidisciplinary methods like Multimedia Learning ( pictures ,graphs, modern tools), E-learning and current technique skills.

Present generation students follow multidisciplinary methods(E-learning,PBL, Case based Learning, Innovative tools, current techniques, modern tools) to solve assignment (problems, scenarios or cases) given by the Instructor. 


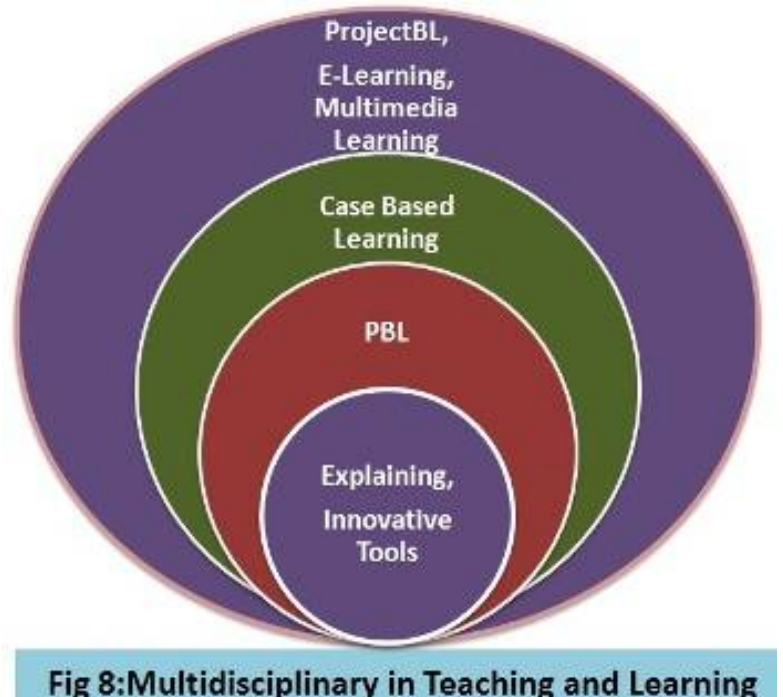

The fig: 8 shows that, depends on the context one or more methods are used to get the solution or for effective teaching and learning process.

The creativity and skill set of the student is growing at ever faster rate and Learning is no longer a one-time affair, because of large variety of high quality learning resources available on the internet and modern tools.

\section{An Illustration on Engineering Education}

Generally in South India, engineering colleges belongs to two types, one type is colleges affiliated to the regional universities, and second type is colleges that are autonomous. Colleges affiliated to the regional universities follows University prescribed syllabus and the colleges that are autonomous follows their syllabus which is approved by the regional universities.

The focus is on the example of teaching and learning methodology on engineering education. The Indian Engineering education can be divided into 4 Phases depends on the curriculum of their course.

\section{Phase-1}

At phase1, the students have different levels of knowledge as a beginner. Here they are new to the professional studies, so the Instructors have to teach them with more basics and students have to habituate the new system of studies.

Here the main method used is explaining with multidisciplinary approaches like-

- Use pictures, schematics, graphs, and simple sketches liberally before, during, and after the presentation of verbal material, Show films.
- Use computer-assisted instruction-sensors respond very well to it.

- Do not fill every minute of class time by lecturing and writing on the board. Provide intervalshowever brief-for students to think about what they have been told .

Phase-2

At phase2, students should be through in basics and are going to apply. Instructors teach them by giving small assignments and students learn by solving those assignments by forming small groups.

In this phase teaching and learning process uses demonstration and PBL method.

- Assign some drill exercises to provide practice in the basic methods being taught but do not give out of you taught. Also provide some open-ended problems and exercises that call for analysis and synthesis.

- Balance material that emphasizes practical problem-solving methods with material that emphasizes fundamental understanding.

- Give students the option of cooperating on homework assignments to the greatest possible extent. Active learners generally learn best when they interact with others; if they are denied the opportunity to do so they are being deprived of their most effective learning tool.

- Appreciate creative solutions, even incorrect ones.

Phase-3

At phase3, Instructors provide problems in the form of cases and sufficient materials to the students. Now they have ability of thinking and sufficient domain knowledge to analyze the case studies and they can frame solution for the cases.

In this phase case based learning with multidisciplinary approaches are used like---

- Follow the scientific method in presenting theoretical material. Formulate solution to the cases and deduce its consequences.

- May wield e-learning and multimedia techniques to get the information on cases and new techniques skills.

- Students in groups apply the gathered information to outline the cases.

- In this they can do it as mini projects to develop mini applications and may use modern tools.

Phase-4 
At phase4, students develop and demonstrate the projects as groups or individual. Instructors guide the students in development.

In this phase project based learning with multidisciplinary approaches are used like---

- E-learning can be wield to get the information or guidelines and current technique skills that can apply to develop the project .

- Multimedia learning can be used for demonstration using modern tools( Adobe Photoshop and Premier to create edit graphics and animation files).

- Students actively explore real-world problems and challenges by investigate and respond to a complex question, problem and acquire a deeper knowledge.

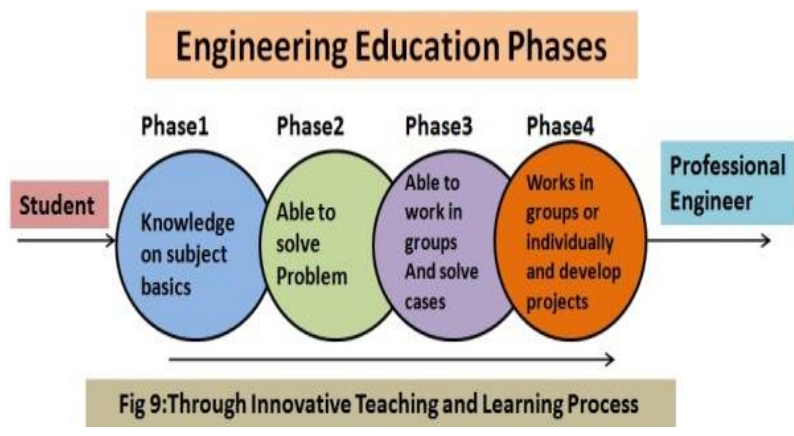

The Fig:9 explains engineering education phases.

Let us consider the example about computer science engineering student, during first phase of education student has ' $\mathrm{C}$ ' subject which is a programming language at first the instructor uses traditional approach to make them comfortable, then explanation continues with drawing diagrams and step by step approach to the professional learning. (Example algorithms and flowcharts).

During the second phase the student has Data Structures (DS), Database Management System(DBMS) subjects and to solve problems in DS student needs to write program for the problem using the basic syntax which is learned in first phase. When it consider other subject as DBMS instructor can give small applications to solve. To write the program or to solve application independently the instructor can give assignments \& ask them to solve (Example in DS write program for stack using ' $C$ ' where as in DBMS small applications like 'Library System” database).

During the third phase the student has case tools subjects like software testing and unified modeling and so on. The instructor taught the subject using multimedia approaches and ask the student to solve cases or scenarios by forming groups. In this phase the instructor make the student to think creatively to get the solution using prior knowledge (Example considering the case as 'Library System' and analyzing it).

During the fourth phase the student has data warehousing and Linux programming subjects, so student develop the project for applications(like feedback System) under the guidelines of instructors with prior knowledge(ie. considering the cases, solving problems which leads to development of the application) .

\section{Conclusion}

Nowadays there is democratization of knowledge and the role of the teacher is changing to that of facilitator. We need to have interactive teaching and this changing role of education is inevitable with the introduction of multidisciplinary approaches. Those approaches are ameliorate the creativity, innovative thinking, problem solving capabilities, able to apply of current technique skills and using of modern tools.

The Engineering Education transforms beginner to a graduate. In this paper it has summarized that the transformation includes innovative teaching and learning process with multidisciplinary approaches at every phase of the engineering education, so that graduates are ready for careers in different regions of the world, work in a variety of contexts, applying current technique skills and using of modern tools for advancement of system.

The teaching and learning process is an never ending one, day by day new methods and approaches are introducing to improve knowledge, which satisfies the global needs.

\section{References}

1.MJ Prince, and Richard M Felder,"Inductive Teaching and Learning Methods: Definitions, Comparisons, and Research Bases", Journal of Engineering Education, Volume 95, Issue 2, pages 123-138, April 2006

2. MJ Prince, and Richard M Felder ,"The Many Faces of Inductive Teaching and Learning", Journal Of College Science Teaching Vol. 36, No. 5, March/April 2007

3. Innovative Methods of Teaching Dr. Damodharan V. S. ACCA, AICWA and Mr. Rengarajan.V AICWA.

4. Richard M Felder,'Learning And Teaching Styles. In Engineering Education”. [Engr.Education, 78(7), 674681 (1988)] Author's Preface — June 2002.

5.Agnew, P. W., Kellerman, A. S. \& Meyer, J. (1996). Multimedia in the Classroom, Boston: Allyn and Bacon. 
6. Tan, O.S., P. Little, S.Y. Hee, and J. Conway,eds. 2002. Problem-based learning:Educational innovation across disciplines. Singapore: Temasek Centre for ProblemBased Learning.

7. Evaluating Teaching Innovation, centre for the study of higher education, By Richard James.

8. Armando Rugarcia--The Future Of Engineering Education,I. A Vision For A New Century, Chem. Engr. Education, 34(1), 16-25 (2000).

9. E-learning methodologies-A guide for designing and developing e-learning courses,Food and Agriculture Organization of the United Nations.Rome, 2011.

10.de Graaff,E., and A.Kolmos,"Characteristics of Problem Based Learning,'International Journal of Engineering Education, Vol.19,No.5,2003,pp.657-662

11.Lynn,Jr.,L.E.,Teaching and Learning withCases, New York:Chatham House Publishers, 1999.

12.Lundeberg,M.,B,Levin, and H.Harrington, Who Learns What from Cases and How? The Research Base For Teaching and Learning with Cases,Mahwah,New Jersey:Lawrence Erlbaum Associates,Inc.,1999. 